\title{
ANALISIS PREFERENSI KONSUMEN TERHADAP KOMODITI TOMAT DAN CABAI MERAH DI KOTA BANDA ACEH
}

\author{
Analysis of Consumer Preferences Towards the Commodity Tomato and Hot Pepper \\ in Banda Aceh
}

\author{
Rahmatun Fauza $^{1}$, Zakiah$^{1}$, Suyanti Kasimin ${ }^{1 *}$ \\ ${ }^{1}$ Program Studi Agribisnis, Fakultas Pertanian, Universitas Syiah Kuala
}

\begin{abstract}
Abstrak. Tomat dan cabai merupakan salah satu dari sembilan bahan pokok yang dibutuhkan oleh setiap rumah tangga. Sebagian besar makanan Nusantara disajikan dengan bahan tomat dan cabai, bahkan tomat dan cabai dapat digunakan dalam kesempatan yang sama. Terjadinya fluktuasi harga pun menyebabkan ketidakstabilan ekonomi pada konsumen karena tomat dan cabai termasuk dalam sembilan bahan pokok. Konsumen membeli kebutuhannya dengan proses yang disebut dengan perilaku konsumen. Prefrensi merupakan salah satu perilaku konsumen. Tujuan penelitian ini adalah untuk menganalisis preferensi konsumen terhadap kombinasi atribut tomat dan cabai merah; serta mengetahui atribut pembelian tomat dan cabai merah yang paling diprioritaskan oleh konsumen. Penelitian ini menggunakan kuesioner sebagai alat bantu penelitian, dengan menggunakan pendekatan deskriptif kualitatif. Analisis yang digunakan dalam penelitian ini adalah analisis konjoin. Hasil penelitian menunjukkan buah tomat yang menjadi preferensi konsumen adalah buah tomat yang berasal dari Medan, dengan harga terendah yaitu Rp 8.000,- dengan daya tahan selama 6-9 hari dan tomat dengan tingkat kesegaran sangat segar dengan rasa buah tomat yang manis.Sedangkan cabai merah yang menjadi preferensi konsumen adalah cabai merah berjenis cabai keriting, dengan harga cabai terendah atau Rp 34.000,- dengan daya tahan cabai selama 5-6 hari dan tingkat kesegaran cabai merah sangat segar dan rasa atau tingkat kepedasan yang pedas. Adapun atribut yang paling diprioritaskan oleh konsumen terhadap tomat dan cabai merah masing-masing jenis tomat dan harga cabai merah.
\end{abstract}

Kata kunci : Preferensi Konsumen, Tomat, Cabai Merah, Analisis Konjoin

Abstract. Tomato and hot pepper is both of the nine staple needed by every household. Most of the national and traditional food served with tomato and hot pepper ingredients, even tomatoes and hot peppers can be used in the same opportunity. The occurrence of any price fluctuations causes by economic instability on the consumer because the tomatoes and hot peppers included in nine staples. Consumers buy its needs with a process called consumer behavior. Preference is one of consumer behavior. The purpose of this research is to analyze consumer preferences towards a combination of attributes of tomatoes and red pepper; as well as knowing the attributes of purchase tomato and red pepper the most prioritised by consumers. This research use the questionnaire and using a descriptive qualitative approach. The analysis used in this study is the conjoint analysis. The results showed the tomatoes into tomato is a fruit consumer preferences that come from the terrain, with the lowest price is Rp 8,000,-with the endurance during the 6-9 days and tomatoes with a degree of freshness is so fresh and flavors of tomato which is sweet. While the red chilli into consumer preferences are red pepper chili-frizzy, priced at the lowest or Rp 34,000 with durability during the 5-6 days and the level of hot pepper freshness is very fresh and the flavor or spiciness level is spicy. As for the attributes of the most prioritized by consumers against tomato and hot pepper each type of tomato and hot pepper price.

Keywords: Consumer Preference, Tomato, Hot Pepper, Conjoint Analysis

\section{PENDAHULUAN}

Tomat dan cabai merupakan salah satu dari sembilan bahan pokok yang dibutuhkan oleh setiap rumah tangga. Sebagian besar makanan Nusantara disajikan dengan bahan tomat dan cabai, bahkan tomat dan cabai dapat digunakan dalam kesempatan yang sama. Terjadinya 
fluktuasi harga pun menyebabkan ketidakstabilan ekonomi pada konsumen karena tomat dan cabai termasuk dalam sembilan bahan pokok.

Pada tahun 2014 produksi tomat mencapai 915.987 ton dengan kontribusi sekitar 7,69\% terhadap produksi sayuran nasional berada pada urutan kelima. Produksi tomat pada tahun 2014 menurun dari tahun sebelumnya yaitu 992.780 ton. Sedangkan produksi cabai pada tahun 2014 meningkat menjadi 1.075.000 ton dari tahun sebelumnya yang hanya mencapai 1.013.270 ton (Direktorat Jenderal Hortikultura, 2014).

Dengan tersedianya tomat maupun cabai dalam jumlah yang banyak maka konsumen akan memiliki peluang lebih besar dalam pemilihan produk sesuai dengan kebutuhannya. Namun apabila ketersediaan tomat maupun cabai terbatas atau dalam jumlah yang sedikit, maka konsumen tidak memiliki pilihan yang banyak untuk menentukan perilaku konsumen tersebut.

Perilaku pembelian konsumen adalah perilaku yang ditunjukkan konsumen dalam memilih dan memutuskan beberapa alternatif produk barang atau jasa untuk selanjutnya dibeli dan dimiliki (Ningsih, 2009). Pada dasarnya, perilaku konsumen adalah perilaku yang berkaitan dengan kemampuan dan usaha konsumen dalam pemenuhan kebutuhannya. Fungsi dari teori perilaku konsumen ini adalah untuk mengetahui dengan pasti mengenai apa yang dibeli oleh konsumen, mengapa, dimana, kapan dan seberapa sering konsumen membeli. Hal ini bertujuan untuk memunculkan kepuasan dan dapat memenuhi kebutuhan konsumen serta menciptakan pendekatan yang baik dalam hal berkomunikasi dengan konsumen.

Preferensi adalah suatu kondisi saat konsumen menentukan keputusan terhadap minat Preferensi memiliki arti kepada pilihan atau memilih. Preferensi konsumen adalah suatu pilihan suka atau tidak suka konsumen terhadap terhadap suatu produk, baik barang ataupun jasa yang dikonsumsi atau digunakan. (Schifman dan Kanuk, 2000). Dalam suatu keadaan, konsumen harus memilih dan memutuskan pilihannya dalam pembelian untuk memuaskan kebutuhan dan mengupayakan pilihannya merupakan yang terbaik. Untuk itu, sebagai produsen sebaiknya mengetahui beberapa hal yang menjadi prioritas konsumen untuk memenuhi permintaan konsumen dalam memenuhi kebutuhannya.

Melihat begitu pentingnya posisi tomat dan cabai dalam pemenuhan kebutuhan pangan konsumen, maka penelitian tentang preferensi konsumen dilakukan untuk mengetahui tingkat kecenderungan (preferensi) konsumen terhadap komoditi tomat dan cabai berdasarkan atributnya yaitu jenis, harga, daya tahan, kesegaran dan rasa. Dengan mengetahui kombinasi atribut komoditi tomat dan cabai yang dipilih konsumen maka akan membantu petani serta peneliti dalam mengembangkan jenis serta varietas komoditi tomat dan cabai yang sesuai dengan tingkat kecenderungan konsumen serta bagi pedagang dapat menyediakan komoditi tomat dan cabai sesuai dengan preferensi konsumen dengan melakukan berbagai upaya alternatif. Tujuan dari penelitian ini adalah untuk menganalisis preferensi konsumen terhadap kombinasi atribut tomat dan cabai merah di Kota Banda Aceh, serta untuk mengetahui atribut yang diprioritaskan oleh konsumen dalam pembelian tomat dan cabai merah.

\section{METODE PENELITIAN}

Penelitian ini menggunakan kuesioner sebagai alat bantu penelitian. Pendekatan yang digunakan dalam penelitian ini adalah pendekatan deskriptif kuantitatif. Objek penelitian ini adalah konsumen yang terdiri dari pedagang, baik pedagang besar mapun pedagang kecil; pengusaha rumah makan, hingga ibu rumah tangga yang berpendapatan tinggi, menengah hingga rendah yang membeli komoditi tomat dan cabai merah di Kota Banda Aceh. Adapun ruang lingkup penelitian dibatasi pada preferensi konsumen terhadap tomat dan cabai di kota Banda Aceh. 
Penelitian ini dilaksanakan di Pasar Peunayong Banda Aceh dengan jumlah sampel yang digunakan sebanyak 60 orang. Untuk memperoleh data-data penelitian dilakukan dengan teknik pengumpulan data primer berupa survei menggunakan kuesioner dan didukung oleh data sekunder.

Metode analisis yang digunakan adalah skala likert dan analisis konjoint. Dalam mengurutkan tingkatan jawaban yang diberikan oleh responden digunakan metode scoring. Metode scoring adalah pemberian nilai yang berupa angka pada jawaban dari pertanyaan yang telah diajukan dalam kuesioner untuk mendapatkan data kuantitatif. Sedangkan analisis konjoin digunakan untuk pemetaan preferensi konsumen. Menurut Supranto (2004) analisis konjoin adalah suatu teknik analisis yang dapat digunakan untuk menentukan tingkat kepentingan relatif berdasarkan persepsi pelanggan yang dibawa oleh suatu produk tertentu dan nilai kegunaan yang muncul dari atribut-atribut produk terkait. Dalam penelitian ini, urutan dalam pemberian skor adalah sebagai berikut:

Tabel 1. Indikator nilai dalam skala likert

\begin{tabular}{lc}
\hline \multicolumn{1}{c}{ Pernyataan Sikap } & Skor \\
\hline Sangat Tidak Setuju & 1 \\
Tidak Setuju & 2 \\
Netral & 3 \\
Setuju & 4 \\
Sangat Setuju & 5 \\
\hline
\end{tabular}

Sumber: Supranto (2003)

\section{Analisis Konjoin}

Analisis konjoin digunakan untuk menjawab hipotesis 1 dan hipotesis 2. Supranto (2004) menyatakan bahwa: "analisis konjoin adalah suatu teknik analisis yang dapat digunakan untuk menentukan tingkat kepentingan relatif berdasarkan persepsi pelanggan yang dibawa oleh suatu produk tertentu dan nilai kegunaan yang muncul dari atribut-atribut produk terkait". Analisis konjoin ini dimanfaatkan salah satunya untuk melihat segmentasi preferensi. Tahapan yang umumnya dilakukan dalam menggunakan analisis konjoin ini adalah sebagai berikut:

1. Merumuskan masalah

2. Mengkontruksi stimuli

3. Menentukan bentuk data input

4. Perhitungan nilai kegunaan taraf atribut

5. Perhitungan tingkat kepentingan atribut

6. Pengukuran korelasi dan keakuratan

Tabel 2. Atribut dan Level Atribut 


\begin{tabular}{|c|c|c|c|c|}
\hline \multirow[t]{2}{*}{ No } & \multicolumn{2}{|c|}{ Tomat } & \multicolumn{2}{|c|}{ Cabai Merah } \\
\hline & Atribut & Taraf Atribut & Atribut & Taraf Atribut \\
\hline \multirow[t]{2}{*}{1} & Jenis & Takengon & Jenis & Cabai Besar \\
\hline & & Medan & & Cabai Keriting \\
\hline \multirow[t]{3}{*}{2} & Harga & Rp 12.000,- & Harga & Rp 38.000,- \\
\hline & & Rp 10.000,- & & Rp 35.000,- \\
\hline & & Rp 8.000,- & & Rp 34.000,- \\
\hline \multirow[t]{3}{*}{3} & Daya Tahan & 1-2 hari & Daya Tahan & 1-2 hari \\
\hline & & 3-5 hari & & 3-4 hari \\
\hline & & 6-9 hari & & 5-6 hari \\
\hline \multirow[t]{3}{*}{4} & Kesegaran & Tidak Segar & Kesegaran & Tidak Segar \\
\hline & & Segar Tidak Merata & & Segar Tidak Merata \\
\hline & & Sangat Segar & & Sangat Segar \\
\hline \multirow[t]{2}{*}{5} & Rasa & Asam & Rasa & Kurang Pedas \\
\hline & & Manis & & Pedas \\
\hline
\end{tabular}

Dalam penelitian ini digunakan 4 (empat) atribut dengan taraf atribut berkisar antara 2 (dua) dan 3 (tiga) taraf atribut. Setiap taraf atribut akan membentuk stimuli yang merupakan kombinasi dari setiap taraf atribut dan akan menentukan nilai kegunaan dan nilai kepentingan dari taraf atribut tersebut (Tabel 2).

Tabel 3. Stimuli untuk preferensi konsumen terhadap komoditi tomat

\begin{tabular}{clc}
\hline Preferensi & \multicolumn{1}{c}{ Kombinasi Atribut } & Responden \\
\hline 1 & Takengon, 8.000, 1-2 hari, segar tidak merata, asam & 60 \\
2 & Medan, 8.000, 3-5 hari, tidak segar, manis & 60 \\
3 & Medan, 10.000, 6-9 hari, tidak segar, asam & 60 \\
4 & Medan, 12.000, 6-9 hari, tidak segar, asam & 60 \\
5 & Medan, 12.000, 3-5 hari, segar tidak merata, asam & 60 \\
6 & Medan, 12.000, 6-9 hari, segar tidak merata, manis & 60 \\
7 & Takengon, 12.000, 1-2 hari, tidak segar, manis & 60 \\
8 & Takengon, 12.000, 3-5 hari, sangat segar, asam & 60 \\
9 & Medan, 8.000, 6-9 hari, sangat segar, manis & 60 \\
10 & Takengon, 8.000, 6-9 hari, tidak segar, asam & 60 \\
11 & Medan, 12.000, 1-2 hari, tidak segar, manis & 60 \\
12 & Takengon, 10.000, 3-5 hari, tidak segar, manis & 60 \\
13 & Medan, 10.000, 1-2 hari, sangat segar, asam & 60 \\
14 & Takengon, 12.000, 6-9 hari, tidak segar, asam & 60 \\
15 & Takengon, 12.000, 6-9 hari, sangat segar, manis & 60 \\
16 & Takengon, 10.000, 6-9 hari, segar tidak merata, manis & 60 \\
\hline
\end{tabular}

Sumber : diolah (2017)

Stimuli untuk preferensi konsumen terhadap komoditi tomat dan cabai yang ditampilkan pada Tabel 3 dan Tabel 4 berikut adalah kombinasi atribut yang telah didesain Orthogonal oleh SPSS. Hal ini menggambarkan suatu rekayasa keadaan yang konsumen hadapi beserta respon konsumen terhadap hal tersebut.

Adanya stimuli dari keempat faktor utama atau atribut (Jenis, Harga, Rasa, Penampilan dan Daya Tahan) dan 13 level atau taraf atribut (2 untuk jenis, 3 untuk harga, 2 untuk rasa, 3 untuk penampilan, dan 3 untuk daya tahan), maka kemungkinan terjadinya kombinasi dari penelitian ini adalah : $2 \times 3 \times 2 \times 3 \times 3=108$ peluang kombinasi dari masing-masing produk 
tomat maupun cabai merah. Secara teoritis, setiap responden diharuskan untuk memilih 108 jenis kombinasi atribut tomat dan 108 jenis kombinasi atribut cabai. Hal itu tentu saja menyulitkan responden dan dinilai kurang efektif maupun praktis. Oleh karena itu, adanya prosedur ortogonal SPSS digunakan untuk menciptakan kombinasi atribut atau design stimuli dari 108 kombinasi atribut tersebut, agar tidak semua kombinasi harus dijawab oleh responden dan dianalisis lebih lanjut. Proses ortogonal ini menghasilkan 16 stimuli untuk masing-masing komoditi baik tomat maupun cabai (Tabel 3 dan Tabel 4).

Tabel 4. Stimuli untuk preferensi konsumen terhadap komoditi cabai merah

\begin{tabular}{clc}
\hline Preferensi & \multicolumn{1}{c}{ Kombinasi Atribut } & Responden \\
\hline 1 & $\begin{array}{l}\text { Cabai keriting, 34.000, 5-6 hari, segar tidak merata, kurang } \\
\text { pedas }\end{array}$ & 60 \\
2 & Cabai besar, 34.000, 3-4 hari, tidak segar, pedas & 60 \\
3 & Cabai besar, 35.000, 1-2 hari, tidak segar, kurang pedas & 60 \\
4 & Cabai besar, 38.000, 3-4 hari, segar tidak merata, kurang pedas & 60 \\
5 & Cabai besar, 38.000, 3-4 hari, segar tidak merata, kurang pedas & 60 \\
6 & Cabai besar, 38.000, 1-2 hari, segar tidak merata, pedas & 60 \\
7 & Cabai keriting, 38.000, 5-6 hari, tidak segar, pedas & 60 \\
8 & Cabai keriting, 38.000, 3-4 hari, sangat segar, kurang pedas & 60 \\
9 & Cabai besar, 34.000, 1-2 hari, sangat segar, pedas & 60 \\
10 & Cabai keriting, 34.000, 1-2 hari, tidak segar, kurang pedas & 60 \\
11 & Cabai besar, 38.000, 5-6 hari, tidak segar, pedas & 60 \\
12 & Cabai keriting, 35.000, 3-4 hari, tidak segar, pedas & 60 \\
13 & Cabai besar, 35.000, 5-6 hari, sangat segar, kurang pedas & 60 \\
14 & Cabai keriting, 38.000, 1-2 hari, tidak segar, kurang pedas & 60 \\
15 & Cabai keriting, 38.000, 1-2 hari, sangat segar, pedas & 60 \\
16 & Cabai keriting, 35.000, 1-2 hari, segar tidak merata & 60 \\
\hline
\end{tabular}

Sumber : diolah (2017)

\section{Uji Validitas dan Realibilitas}

Uji validitas digunakan untuk menunjukan sejauh mana suatu alat ukur (kuesioner) yang digunakan telah mengukur informasi yang diperlukan. Uji ini dilakukan dengan mengukur korelasi antara variabel/item dengan skor total variabel. Digunakan validitas konstruk yaitu mencari korelasi antara masing-masing pertanyaan dengan skor total. Uji validitas ini dilakukan dengan menggunakan Uji Korelasi Pearson's yang dirumuskan sebagai berikut (Ghozali, 2011)

$$
r_{x y}=\frac{n \sum x y-\sum x \sum y}{\sqrt{\left\{\left(n \sum x^{2}\right)-\left(\sum x\right)^{2}\right\}\left\{\left(n \sum y^{2}\right)-\left(\sum y\right)^{2}\right\}}}
$$

Keterangan :

$$
\begin{array}{ll}
r_{x y} & =\text { Koefisien Korelasi Pearson's } \\
x & =\text { Skor pertanyaan untuk setiap subjek } \\
y & =\text { Skor total } \\
x y & =\text { Skor pertanyaan dan skor total } \\
n & =\text { Jumlah sampel }
\end{array}
$$

Jika koefisien korelasi antara skor suatu indikator dengan skor total keseluruhan $\left(\mathrm{r}_{\mathrm{xy}}\right) \geq$ nilai kritis $\mathrm{r}\left(\mathrm{r}_{\text {tabel }}\right)$ maka dapat dinyatakan instrumen tes yang diujicobakan tersebut dianggap valid. 
Uji reliabilitas dilakukan untuk mengetahui sejauh mana alat ukur tersebut dapat dipercaya atau untuk mengukur kekonsistenan alat ukur tersebut. Alat pengujiannya yaitu dengan mencari nilai koefisien Alpha-Cronbach, dengan rumus :

$$
r=\frac{k}{k-1}\left(1-\frac{\sum \sigma_{i}^{2}}{\sigma^{2}}\right)
$$

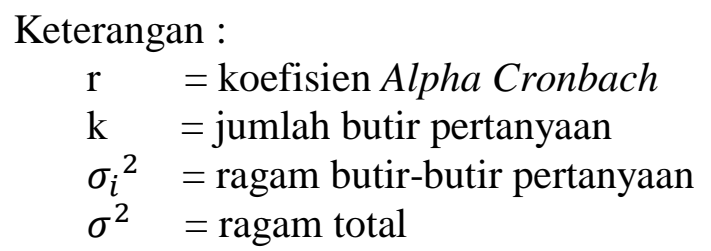

Jika koefisien Alpha Cronbach $\mathrm{r} \geq$ nilai kritis $\mathrm{r}\left(\mathrm{r}_{\text {tabel }}\right)$ maka dapat dinyatakan instrumen tes yang diujicobakan tersebut reliabel. Apabila alat ukur tersebut dinyatakan valid dan reliabel maka dapat dilakukan proses selanjutnya (Ghozali, 2011).

\section{HASIL DAN PEMBAHASAN}

\section{Uji Validitas dan Realibilitas Atribut Buah Tomat}

Didapatkan nilai $r$ tabel sebesar 0,2452. Dengan nilai signifikansi sebesar 5\% maka didapatkan 4 preferensi yang tidak valid dari 16 preferensi yang ditawarkan. Hal ini disebabkan karena dalam desain tersebut merupakan keadaan yang paling tidak diterima oleh responden, dan sangat terpaksa harus memilih keadaan tersebut. Dalam hal ini, ada beberapa hal yang menjadi pertimbangan konsumen, seperti ketidaksesuaian harga dengan keinginan konsumen, contohnya jika produk terlalu murah dengan kondisi yang tidak segar, konsumen juga turut mempertimbangkan keadaan tersebut. Selain itu, jenis tomat juga menjadi hal yang menjadi salah satu hal yang dipertimbangkan oleh konsumen. Sedangkan untuk hasil uji realibilitas uji realibilitas dapat diketahui bahwa kuesioner yang digunakan sudah realiable atau konsisten karena nilai $r$ hitung $>r$ tabel (Ghozali, 2011), didapatkan nilai Cronbach's Alpha sebesar 0,670, sehingga hasil menunjukkan bahwa kuesioner adalah realiabel karena nilai berada lebih besar dibandingkan dengan 0,2452 ( $\mathrm{r}$ tabel).

\section{Preferensi Konsumen Terhadap Kombinasi Atribut Buah Tomat}

Tabel 5. Hasil Analisis Preferensi Konsumen Terhadap Buah Tomat

\begin{tabular}{llrr}
\hline & & Utility Estimate & Standar Error \\
\hline \multirow{2}{*}{ Jenis_Tomat } & Takengon & $-0,385$ & 0,071 \\
& Medan & $\mathbf{0 , 3 8 5}$ & 0,071 \\
& 12000 & $-0,106$ & 0,095 \\
Daya_Tahan & 10000 & 0,005 & 0,112 \\
& $\mathbf{8 0 0 0}$ & $\mathbf{0 , 1 0 1}$ & 0,112 \\
& $\mathbf{6 - 9}$ hari & $\mathbf{0 , 0 5 6}$ & 0,095 \\
Kesegaran & 3-5 hari & 0,028 & 0,112 \\
& 1-2 hari & $-0,084$ & 0,112 \\
& Tidak Segar & $-0,114$ & 0,095 \\
Rasa & Segar Tidak Merata & $-0,081$ & 0,112 \\
& Sangat Segar & $\mathbf{0 , 1 9 4}$ & 0,112 \\
Constant & Asam & $-0,029$ & 0,071 \\
& Manis & $\mathbf{0 , 0 2 9}$ & 0,071 \\
Sumber & & 3,814 & 0,082 \\
\hline
\end{tabular}

Sumber : Hasil Pengolahan data (2017) 
Tabel 5 menunjukkan hasil analisis konjoin untuk buah tomat yang diinginkan konsumen. Dari hasil estimasi nilai kegunaan (part-worth) dapat dilihat bahwa jenis tomat atau asal tomat yang diinginkan konsumen adalah tomat yang berasal dari Medan, ditunjukkan dengan nilai part-worth sebesar 0,385. Sedangkan untuk atribut harga, konsumen memilih harga buah tomat terendah yaitu Rp 8.000,- yang ditunjukkan dengan nilai part-worth sebesar 0,101 . Untuk atribut daya tahan, konsumen memilih buah tomat dengan daya tahan tertinggi yaitu 6-9 hari dengan nilai part-worth sebesar 0,056. Atribut kesegaran yang diinginkan konsumen adalah buah tomat dengan tampilan sangat segar, ditunjukkan dengan nilai partworth sebesar 0,194, dan untuk atribut rasa konsumen cenderung memilih tomat dengan rasa manis yang ditunjukkan dengn part-worth sebesar 0,029.

Buah tomat (Solanum lycopersicum L.) yang menjadi preferensi konsumen dapat dilihat dari nilai kegunaan (utility values) yang terbesar diantara atribut yang disajikan. Adapun buah tomat yang menjadi preferensi konsumen secara keseluruhan adalah buah tomat yang berasal dari Medan, harga terendah atau Rp 8.000,- ,dengan daya tahan buah tomat selama 6-9 hari, dengan tingkat kesegaran sangat segar dan buah tomat dengan rasa manis.

Spesifikasi buah tomat yang menjadi preferensi konsumen dalam penelitian ini sebagian besar muncul karena didalam paradigma konsumen sudah terbentuk pemikiran bahwa tomat yang berasal dari Medan cenderung lebih tahan lama, rasanya manis dan lebih segar secara visual. Sekalipun harga tomat yang berasal dari Medan ini lebih mahal dibandingkan tomat lokal atau tomat Takengon, konsumen lebih banyak memilih tomat Medan untuk dibeli.

Atribut yang memiliki nilai kepentingan relatif (importance values) menunjukkan bahwa atribut tersebut yang paling diprioritaskan oleh responden. Adapun atribut yang memiliki nilai paling rendah menandakan bahwa atribut tersebut merupakan faktor yang paling tidak diperhatikan atau tidak diprioritaskan oleh responden. Tabel berikut menunjukkan hasil interpretasi data analisis konjoin yang menyajikan nilai kepentingan relatif dari atribut-atribut preferensi buah tomat yang diteliti dalam penelitian ini:

Tabel 6. Nilai Kepentingan Relatif Atribut Buah Tomat Secara Keseluruhan

\begin{tabular}{cc}
\hline Atribut & Nilai Kepentingan Konsumen (\%) \\
\hline Jenis Tomat & 28,58 \\
Harga & 17,09 \\
Daya Tahan & 20,65 \\
Kesegaran & 22,79 \\
Rasa & 10,88 \\
\hline
\end{tabular}

Sumber : data primer diolah (2017)

Tabel 6 di atas menunjukkan responden secara keseluruhan lebih memprioritaskan atribut jenis tomat $(28,58 \%)$ dibandingkan dengan atribut buah tomat yang lainnya. Hal ini terjadi karena mindset konsumen telah terbentuk bahwa tomat yang berasal dari Medan lebih baik, baik secara visual melalui kesegaran, daya tahan lebih lama, sekalipun harganya lebih tinggi dibandingkan tomat lokal atau tomat Takengon. Selanjutnya konsumen secara keseluruhan memprioritaskan atribut kesegaran dengan nilai kepentingan sebesar $22,79 \%$. Hal ini terjadi karena konsumen melihat dari tampilan fisik tomat yang akan dibeli dan karena kesegaran adalah hal yang pertama kali tampak secara visual. Pada peringkat ketiga, konsumen memprioritaskan daya tahan tomat dengan nilai kepentingan atribut sebesar 20,65\%. Hal ini terjadi karena konsumen juga memikirkan keamanan pangan terhadap sesuatu yang akan dikonsumsi. Pada peringkat keempat, konsumen memprioritaskan atribut harga dengan nilai kepentingan sebesar 17,09\%. Hal ini disebabkan karena nilai tomat relatif mudah dijangkau oleh konsumen, dan konsumen mementingkan jenis tomat terlebih dahulu tanpa memikirkan 
atribut harga. Rasa merupakan hal yang paling tidak diprioritaskan oleh konsumen dalam pembelian buah tomat. Hal ini disebabkan karena konsumen menilai rasa buah tomat tidak terlalu mempengaruhi dalam penggunaannya.

\section{Uji Validitas dan Realibilitas Atribut Cabai Merah}

Didapatkan nilai $r$ tabel sebesar 0,2452. Dengan nilai signifikansi sebesar 5\% maka didapatkan 2 preferensi yang tidak valid dari 16 preferensi yang ditawarkan. Hal ini terjadi karena dalam desain tersebut sangat tidak sesuai dengan keinginan konsumen sehingga konsumen dengan terpaksa harus memilih keadaan yang tersedia. Hal ini juga berkaitan dengan nilai kepentingan konsumen yang lebih mementingkan harga cabai dan jenis cabai yang dipilih yaitu cabai keriting yang memiliki rasa yang lebih khas. Sedangkan untuk hasil uji realibilitas uji realibilitas dapat diketahui bahwa kuesioner yang digunakan sudah realiable atau konsisten karena nilai $r$ hitung > r tabel (Ghozali, 2011), didapatkan nilai Cronbach's Alpha sebesar 0,738, sehingga hasil menunjukkan bahwa kuesioner adalah realiabel karena nilai berada lebih besar dibandingkan dengan 0,2452 ( $\mathrm{r}$ tabel).

\section{Preferensi Konsumen terhadap Kombinasi Atribut Cabai Merah}

Selain preferensi buah tomat, preferensi konsumen yang akan dibahas dalam penelitian ini adalah preferensi cabai merah (Capsicum annuum L.). Hasil dari proses analisis konjoin untuk preferensi konsumen dalam memilih cabai merah secara keseluruhan dapat dilihat dari tabel berikut:

Tabel 7. Preferensi Konsumen Terhadap Cabai Merah

\begin{tabular}{llrr}
\hline & & Utility Estimate & Standar Error \\
\hline Cabai & Cabai Besar & $-0,024$ & 0,057 \\
& Cabai Keriting & $\mathbf{0 , 0 2 4}$ & 0,057 \\
& 38000 & $-0,221$ & 0,076 \\
\multirow{3}{*}{ Daya_Tahan } & 35000 & $-0,194$ & 0,089 \\
& $\mathbf{3 4 0 0 0}$ & $\mathbf{0 , 4 1 5}$ & 0,089 \\
& 1-2 hari & $-0,035$ & 0,076 \\
Kesegaran & 3-4 hari & $-0,018$ & 0,089 \\
& 5-6 hari & $\mathbf{0 , 0 5 3}$ & 0,089 \\
& Tidak Segar & $-0,107$ & 0,076 \\
Rasa & Segar Tidak Merata & 0,039 & 0,089 \\
& Sangat Segar & $\mathbf{0 , 0 6 8}$ & 0,089 \\
Constant & Kurang Pedas & $-0,070$ & 0,057 \\
& Pedas & $\mathbf{0 , 0 7 0}$ & 0,057 \\
\hline
\end{tabular}

Sumber: data primer diolah (2017)

Tabel 7 menunjukkan hasil analisis konjoin untuk cabai merah yang diinginkan konsumen. Dari hasil estimasi nilai kegunaan (part-worth) dapat dilihat bahwa jenis cabai yang diinginkan konsumen adalah cabai keriting, ditunjukkan dengan nilai part-worth sebesar 0,024. Sedangkan untuk atribut harga, konsumen memilih harga buah cabai terendah yaitu Rp 34.000,yang ditunjukkan dengan nilai part-worth sebesar 0,415. Untuk atribut daya tahan, konsumen memilih buah tomat dengan daya tahan tertinggi yaitu 5-6 hari dengan nilai part-worth sebesar 0,053. Atribut kesegaran yang diinginkan konsumen adalah cabai merah dengan tampilan sangat segar, ditunjukkan dengan nilai part-worth sebesar 0,068. Sedangkan untuk atribut rasa 
konsumen lebih memilih cabai dengan tingkat kepedasan yang tinggi atau cabai dengan rasa pedas yang ditunjukkan dengan nilai part-worth sebesar 0,070.

Dari tabel 7 juga dapat dilihat bahwa konsumen cenderung memilih atribut buah cabai merah dengan nilai kegunaan terbesar dari setiap level atribut. Sebagian besar responden memilih cabai keriting untuk konsumsinya karena sebagian besar responden menilai cabai keriting lebih tahan lama, dan memiliki rasa yang sangat pedas. Sesuai dengan selera konsumen yang didominasi oleh masyarakat Aceh. Sedangkan cabai merah besar akan lebih mudah layu dibandingkan cabai merah keriting, disamping juga memiliki tingkat kepedasan yang lebih rendah dibandingkan cabai merah keriting. Tabel berikut menunjukkan hasil interpretasi data analisis konjoin yang menyajikan nilai kepentingan relatif dari atribut-atribut preferensi cabai merah yang diteliti dalam penelitian ini:

Tabel 8. Nilai Kepentingan Relatif Atribut Cabai Merah Secara Keseluruhan

\begin{tabular}{cc}
\hline Atribut & Nilai Kepentingan Konsumen (\%) \\
\hline Jenis Tomat & 13,32 \\
Harga & 30,29 \\
Daya Tahan & 23,69 \\
Kesegaran & 21,62 \\
Rasa & 11,08 \\
\hline
\end{tabular}

Sumber : data primer diolah (2017)

Sama halnya dengan analisis konjoin pada buah tomat, atribut yang memiliki nilai kepentingan relatif (importance values) menunjukkan bahwa atribut tersebut yang paling diprioritaskan oleh responden. Adapun atribut yang memiliki nilai paling rendah menandakan bahwa atribut tersebut merupakan faktor yang paling tidak diperhatikan atau tidak diprioritaskan oleh responden.

Berdasarkan Tabel 8 diatas, dapat dilihat bahwa responden secara keseluruhan memprioritaskan harga cabai dengan nilai kepentingan 30,29\%. Hal ini terjadi karena adanya fluktuatif harga dari komoditi cabai merah sendiri diikuti dengan adanya hari-hari besar masyarakat Aceh. Namun berbeda dengan tomat, atribut jenis cabai merah dianggap tidak penting dalam penelitian ini, karena berada di peringkat keempat nilai kepentingan dari konsumen yaitu sebesar $13,32 \%$. Atribut kedua yang diprioritaskan adalah daya tahan cabai $(23,69 \%)$. Hal ini disebabkan karena daya tahan cabai lebih rendah dibandingkan dengan daya tahan tomat. Atribut cabai merah ketiga yang diprioritaskan oleh konsumen adalah kesegaran cabai $(21,62 \%)$. Berbanding lurus dengan daya tahan cabai, cabai yang sudah keriput dan berwarna kehitaman, akan membuat konsumen ragu untuk mengkonsumsinya. Terlebih jika kadar air yang terkandung dalam cabai sudah terlalu tinggi, maka hal itu juga akan mempermudah pembusukan cabai tersebut. Sedangkan atribut yang terakhir yang diprioritaskan oleh konsumen adalah rasa cabai (11,08\%). Hal ini disebabkan karena rasa cabai dengan tingkat kepedasan yang tidak berbeda secara signifikan sehingga sebagian besar responden menganggap bahwa rasa cabai merah, dalam hal ini cabai keriting dan cabai besar, adalah sama.

\section{KESIMPULAN DAN SARAN}

\section{Kesimpulan}

Berdasarkan hasil penelitian dan pembahasan, maka dapat disimpulkan beberapa hal, yaitu:

1. Buah tomat (Solanum lycopersicum L.) yang menjadi preferensi konsumen dapat dilihat dari nilai kegunaan (utility values) yang terbesar diantara atribut yang 
disajikan. Adapun buah tomat yang menjadi preferensi konsumen secara keseluruhan adalah buah tomat yang berasal dari Medan dengan nilai part-worth sebesar 0,385; tomat dengan harga terendah atau Rp 8.000,- dengan nilai part-worth sebesar 0,101 ; tomat dengan daya tahan buah selama 6-9 hari dengan nilai partworth 0,056 ; tomat dengan tingkat kesegaran sangat segar dengan nilai part-worth sebesar 0,194 dan buah tomat dengan rasa manis dengan nilai part-worth sebesar 0,029 .

Cabai merah (Capsicum annuum L.) yang menjadi preferensi konsumen dapat dilihat dari nilai kegunaan (utility values) yang terbesar diantara atribut yang disajikan. Adapun cabai merah yang menjadi preferensi konsumen secara keseluruhan adalah cabai merah keriting dengan nilai part-worth sebesar 0,24 ; dengan harga cabai merah terendah atau $\mathrm{Rp} 34.000$,- dengan nilai part-worth 0,415 ; cabai merah dengan daya tahan selama 5-6 hari dengan nilai part-worth sebesar 0,53; tingkat kesegaran cabai merah dengan part-worth sebesar 0,068 dan tingkat kepedasan cabai merah yang pedas dengan part worth sebesar 0,70.

2. Responden secara keseluruhan lebih memprioritaskan atribut jenis tomat $(28,58 \%)$ dibandingkan dengan atribut buah tomat yang lainnya. Hal ini terjadi karena mindset konsumen telah terbentuk bahwa tomat yang berasal dari Medan lebih baik, baik secara visual melalui kesegaran, daya tahan lebih lama, sekalipun harganya lebih tinggi dibandingkan tomat lokal atau tomat Takengon. Untuk komoditi cabai merah, responden secara keseluruhan memprioritaskan harga cabai dengan nilai kepentingan 30,29\%. Hal ini terjadi karena adanya fluktuatif harga dari komoditi cabai merah sendiri diikuti dengan kebiasaan sosial budaya masyarakat Aceh, seperti kenduri dan perayaan keagamaan lainnya. Selain itu, fluktuasi harga juga disebabkan karena produksi cabai yang bergantung pada cuaca.

\section{Saran}

Berdasarkan kesimpulan diatas, maka penulis mengemukakan saran sebagai berikut:

1. Hendaknya pemerintah menerapkan kebijakan berupa lembaga yang melakukan sotasi berdasarkan kualitas terhadap komoditi pertanian yang akan dipasarkan. Hal ini akan mempermudah konsumen dalam pemilihan produk yang akan dibeli. Selain itu, hal ini akan menjaga harga tingkat petani yang tidak terlalu rendah. Begitupun sebaiknya dilakukannya sosialisasi mengenai manfaat mengkonsumsi produk lokal.

2. Pedagang sebaiknya melakukan alternatif lain dalam mengupayakan agar tetap menjual produk tetap berkualitas sampai ke tangan konsumen. Upaya yang dilakukan diantaranya adalah menyimpan komoditi yang telah dipacking secara modern di dalam ruangan pendingin.

\section{DAFTAR PUSTAKA}

Adiyoga, W dan Nurmalinda. 2012. Analisis Konjoin Preferensi Konsumen terhadap Atribut Produk Kentang, Bawang Merah, dan Cabai Merah. Jurnal Hortikultura. 22(3):292302.

Adiyoga, W. 2011. Faktor-faktor yang Mempengaruhi Perilaku dan Keputusan Konsumen untuk Membeli Kentang, Bawang Merah dan Cabai Merah. Jurnal Hortikultura. 21(3):280-294.

Ameriana, M. 1998. Perbaikan Kualitas Sayuran Berdasarkan Preferensi Konsumen. Jurnal Monograf No 17. Balai Penelitian Tanaman Sayuran. Pusat Penelitian dan 
Pengembangan Hortikultura. Badan Penelitian dan Pengemangan Pertanian. ISBN : 979-8304-29-2.

Ameriana, M. 1995. Pengaruh Petunjuk Kualitas Terhadap Persepsi Konsumen Mengenai Kualitas Tomat. Penelitian Hort XXVII (4):1-7

Ashari, S., 2006. Hortikultura Aspek Budidaya. Penerbit UI Press. Universitas Indonesia, Jakarta.

Badan Standardisasi Nasional. SNI Cabai Merah 01-4480-1998.. Indonesia.

Badan Standardisasi Nasional. SNI Buah Tomat Segar 01-3162-1992. Indonesia.

Besanko, D dan Braeutigam, R. R. 2008. Microeconomics. John Wiley and Sons. Asia.

Chan-Halbrendth, C., E. Zhilima., G. Sisior., D. Imami. 2010. Consumer Preferences for Olive Oil in Tirana, Albania. International Food and Agribusiness Management Review. 13(3). 55-74.

Dasipah, E., H. Budiyono, dan M. Julaeni. 2010. Analisis Perilaku Konsumen dalam Pembelian Produk Sayuran di Pasar Modern Kota Bekasi. Jurnal Agribisnis dan Pengembangan Wilayah. 1(2): 24-37.

Direktorat Jenderal Hortikultura. 2015. Statistik Produksi Hortikultura. Kementian Pertanian. Jakarta.

Engel J. F., Blackwell dan Miniard. 1994. Perilaku Konsumen. Jilid II. Edisi keenam. Jakarta :Binarupa Aksara.

Engel, Blackwell, Miniard. 2012. Perilaku Konsumen. Binarupa Aksara. Tangerang.

Firmanto, B.H. 2011. Sukses Bertanam Tomat Secara Organik. Angkasa. Bandung. Hal 10-11.

Fuadi, A., S. Kasimin, E. Susanti. 2017. Analisis Faktor-Faktor yang Mempengaruhi Harga Jual Kedelai Tingkat Petani Pada Sentral Produksi di Kecamatan Peudada Kabupaten Bireuen. Jurnal Ilmiah Mahasiswa Pertanian Unsyiah. Vol. 2 No. 2.

Ghozali, I. 2011. Aplikasi Analisis Multiariate dengan Program IBM SPSS 19. Edisi Kelima. Universitas Diponegoro. Semarang.

Gitosudarmo, Indriyono. 1995. Manajemen Pemasaran. Edisi Pertama. BPFE Yogyakarta.

Hair, J. F., William C. Black, Barry J. Babin, Rolph. E. Anderson, dan R.L. Tatham.2006. Multivariate Data Analysis, Sixth Edition. Pearson Education Inc. New Jersey.

Indarto, RP. 2011. Analisis Preferensi Konsumen Terhadap Bundling Kartu GSM dengan Smartphone. Universitas Indonesia. Thesis.

Jones, B Jr. 2008. Tomato Plant Culture; In the Field, Greenhouse and Home Garden. CRC Press. New York.

Kasimin, S. 2013. Keterkaitan Produk dan Pelaku dalam pengembangan Agribisnis Hortikultura Unggulan di Provinsi Aceh. Jurnal Manajemen dan Agribisnis. Volume 10 No. 2

Kementerian Pertanian Republik Indonesia. 2016. Statistik Pertanian. Jakarta. epublikasi.setjen.pertanian. go.id/

Kotler P, dan Armstrong, G. 2012. Principles of Marketing.Edisi ke-14.New Jersey (US): Pearson Prentice Hall.

Kotler P, dan Armstrong, G. 2006. Prinsip-Prinsip Pemasaran. Terjemahan: Bob Sabran, Jilid 1, Ed ke-12. Jakarta (ID): Erlangga. 613 hal.

Luthfiani, Dian. 2016. Preferensi Konsumen Terhadap Furnitur di Banda Aceh. Skripsi. Universitas Syiah Kuala. Banda Aceh.

Marbun, DNA, Diana C, Siti K. 2015. Analisis Faktor-Faktor yang Mempengaruhi Fluktuasi Harga Tomat di Kota Medan. Skripsi. Universitas Sumatera Utara. Medan.

Margono. 2004. Metodologi Penelitian Pendidikan. Rineka Cipta. Jakarta.

Martono, Nanang. 2010. Metode Penelitian Kuantitatif. PT. Raja Grafindo Persada. Jakarta.

Marwan, Asri. 1990.Marketing. Yogyakarta: BPFE - UGM. 
Muzdalifah. 2012. Kajian Preferensi Konsumen Terhadap Buah-Buahan Lokal di Kota Banjarbaru. Jurnal Agribisnis Perdesaan. Volume 2 Nomor 4 Desember 2012. Universitas Lambung Mangkurat. Banjarbaru.

Mowen, John., M. Minor. 2009. Perilaku Konsumen. Edisi 5. Erlangga. Jakarta.

Nauly, D. Fluktuasi dan Disparitas Harga Cabai di Indonesia. Jurnal Agrosains dan Teknologi. Vol. 1 Nomor 1. Universitas Muhammadiyah Jakarta.

Nicholson, W. 1997. Intermediate Microeconomics and Its Application. 7th Edition. The Dryden Press.

Ningsih, ER. 2009. Manajemen Pemasaran Syariah: hal 77. Gelisa. Kudus.

Nugroho, C,A. 2013. Penerapan Analisis Konjoin Dalam Menentukan Persepsi Mahasiswa Matematika Terhadap Dosen (Studi Kasus : Program Studi Matematika Fakultas Mipa Universitas Pakuan). Skripsi. Universitas Pakuan. Bogor.

Purwati, E. Dan Khairunnisa. 2008. Budidaya Tomat Daratan Rendah dengan Varietas Unggul serta Tahan Hama dan Penyakit. Penebar Swadaya, Jakarta.

Prajnanta, F. 1999. Agribisnis Cabai Hibrida. Penebar Swadaya, Jakarta.

Prayudi, B. 2010. Budidaya dan Pasca Panen Cabai Merah. Badan Penelitian dan Pengembangan Pertanian. Balai Pengkajian Teknologi Pertanian. Jawa Tengah.

Rahardjo, CR. 2016. Faktor yang Menjadi Preferensi Konsumen dalam Membeli Produk Frozen Food. Jurnal PERFORMA. ISSN:2527-4635. Volume 1 Nomor 1. Universitas Ciputra.

Riawan, N, Tensiska, Marsetio. 2010. Pemanfaatan Ekstrak Kencur dan Sereh Dapur Untuk Meningkatkan Daya Tahan Simpan Tomat Segar Kultivar Martha (Lycopersicum esculentum Mill) yang Disimpan Pada Suhu Ruang. Jurnal Teknotan Vol 4, No 1. Universitas Padjajaran. Bandung.

Richard CR dan Smith E. 2004.The Value of Apple Characteristics to Wholesalers in Western Canada: A hedonis Approach. Canadian Journal of Plant Science. 84(3): 829-835.

Riska, I.Y, S. Mulya, Padmaningrum. 2012. Analisis Preferensi Konsumen Pasar Tradisional Terhadap Buah Jeruk Lokal dan Buah Jeruk Impor Di Kabupaten Kudus. E-Jurnal Agrista - ISSN 2302-1713. 1(2). Universitas Sebelas Maret Surakarta.

Rompas, J.P. 2001 Efek Isolasi Bertingkat C. Capsici Terhadap Penyakit Antraknosa pada Buah Cabai di Sumatera Barat. Proseding Kongres Nasional XLV dan Seminar Ilmiah. Palembang. Perhimpunan Fitopatologi Indonesia. 187-190.

Salvatore, D. 1992. Theory and Problems of Microeconomics Theory. Third Edition. Mc Graw Hill.International Book Company.

Santoso, S. 2012. Aplikasi SPSS pada Statistik Multivariat. PT. Elex Media Komputindo, Jakarta.

Schiffman dan Kanuk. 2007. Perilaku Konsumen. Edisi Kedua. Jakarta: PT. Indeks Gramedia. Simamora, B. 2003. Membongkar Kotak Hitam Konsumen. Gramedia Pustaka Utama. Jakarta.

Soetiarso, T.A. 2010. Preferensi Konsumen Terhadap Atribut Kualitas Empat Jenis Sayuran Minor. Jurnal Hortikultura 20(4): 398-407. Balai Penelitian Tanaman Sayuran. Bandung.

Sugiyono, 2010. Metode Penelitian Pendidikan. Alfabeta. Bandung, hlm: 117

Sukirno, S. 2002. Teori Ekonomi Mikro. Cetakan Keempat Belas. Rajawali Press. Jakarta.

Sulistyowati, L., D. Ma'mun., M. Ameriana dan W. Adiyoga. 1997. Idiotipe Kualitas Cabai dan Kentang Berdasarkan Selera dan Kebutuhan Konsumen Rumah Tangga Konsumen Lembaga dan Industri. Laporan Kerjasama UNPAD, Balitsa dan ARMP II.

Sumarwan, U. 2004. Perilaku Konsumen : Teori dan Penerapannya dalam Pemasaran. Jakarta: Ghalia Indonesia.

Supranto, J. 2003. Metode Penelitian Hukum Statistik. PT. Rineka Cipta. Jakarta. 
Tugiyono. 2005. Tanaman Tomat. Agromedia Pustaka. Jakarta:250 halaman.

Villareal, R.L and J.C. Moomaw. 1979. Proocedings of the First International Symposium on the Tropical Tomato. 23-27 October 1979. Shanhua. Taiwan.

Widodo, P. 2010. Hubungan Antara Atribut Produk Terhadap Keputusan Pembelian Minuman Teh dalam Kemasan. CEFARS: Jurnal Agribisnis dan Pengembangan Wilayah Vol 2 No 1

Wirartha, I. M. 2006. Metodologi Penelitian Sosial Ekonomi. Andi. Yogyakarta.

Yasmin, T. R., W. D. Prastiwi, dan M. Handayani. 2017. Analisis Konjoin Preferensi Konsumen Sayuran Hidroponik Agrofarm Bandungan Kabupaten Semarang. Jurnal Sosial Ekonomi Pertanian. ISSN 2580-0566. 1(1) 85-93. 